\title{
New Surrogate Markers for Coronary Heart Disease
}

\author{
Gorm B. Jensen \\ Department of Cardiology, Copenhagen University Hospital, Hvidovre, Denmark
}

Atherosclerosis develops in many vascular domains, but varies in severity from one vascular bed to another in the same individual. Most often, the aorta is the seat of the most advanced changes, but clinical disease is of course linked mainly to atherosclerosis occurring in the coronary arteries, the extracranial arteries to the brain and the arteries to the lower extremities. Subclinical atherosclerosis can be detected as intima-media thickening (IMT), as demonstrated in the report of Srámek et al. [1] in the present issue of Heart Drug and in many other publications. The purpose of the study of Šrámek et al. [1] was to determine whether IMT in the femoral artery as compared to IMT in the carotid artery might be a valid surrogate for the detection of coronary artery disease (CAD). The main finding was that IMT in the common femoral artery was more closely associated with CAD than IMT in the carotid artery. Intuitively, the finding is not surprising, as combined disease occurs frequently. While this finding may represent a refinement of the present methodology, the study populations, especially the control sample, were small and highly selected, and the finding needs to be confirmed in larger, prospective series.

The gold standard for CAD is coronary arteriography. Noninvasive markers have been used in clinical medicine for many decades for the diagnosis of CAD. These markers, i.e. exercise electrocardiography, radionuclide myocardial scintigraphy and various applications of echocardiography, belong to the core of clinical cardiology. Their application and interpretation as well as their limitations are exceedingly well described in the cardiological literature. At the other end of the spectrum stands risk factor assessment based on coronary risk factors such as elevated serum cholesterol, elevated blood pressure, cigarette smoking and many others. These risk factors have been validated time and again in prospective epidemiological studies, the prime example being the Framingham study [2]. Furthermore, risk factor reduction by appropriate treatment has conclusively been shown to reduce the incidence of clinical coronary heart disease [3, 4].

Clinical cardiology has increasingly moved towards the preventive aspects, and in particular what might be termed intermediate prevention, that is, the prevention of progression from high-risk and subclinical disease to clinically apparent heart disease. The occurrence of high-risk or subclinical disease triggers the application of risk reduction, in particular lipid-lowering therapy, aggressive antihypertensive treatment and behavioral modification with regard to smoking, obesity and physical exertion.

In this context, three 'new' surrogate markers for CAD are extremely interesting.

The demonstration of calcium deposits in coronary arteries by electron beam tomography (EBT) has been shown to correlate well with the presence of obstructive CAD and the clinical prognosis [5, 6]. What is not known is whether preventive treatment based on the findings of EBT may in fact reduce the subsequent occurrence of clin-

\begin{tabular}{ll}
\hline KARGER & ( ) 2001 S. Karger AG, Basel \\
Fax +4161306 1234 & 1422-9528/01/0015-0242\$17.50/0 \\
$\begin{array}{l}\text { E-Mail karger@karger.ch } \\
\text { www.karger.com }\end{array}$ & $\begin{array}{l}\text { Accessible online at: } \\
\text { www.karger.com/journals/hed }\end{array}$
\end{tabular}

Gorm B. Jensen, MD, DMSc

Head, Department of Cardiology

Copenhagen University Hospital Hvidovre

DK-2650 Hvidovre (Denmark)

Tel. +45 36322 944, Fax +45 36323 755, E-Mail gorm.jensen@hh.hosp.dk 
ical manifestations of CAD, as recently discussed by Grundy [7]. There is an obvious need for further studies of EBT in the context of standard risk assessment as well as intermediate intervention studies aimed at reducing calcium deposits in the coronary arteries and studies of the effect of preventive treatment on clinical endpoints in patients in whom risk assessment is based on EBT. Intuitively, EBT is a very attractive instrument for risk assessment, as it is aimed directly at the coronary artery plaque, but there is a long way to go before it can be applied clinically.

Endothelial dysfunction measured by flow-mediated vasodilatation (FDM) as first described by Celermajer et al. [8] has received much attention in recent years. The study of FDM is noninvasive, does not involve ionizing radiation and is highly reproducible. Endothelial dysfunction is associated with coronary risk factors and overt clinical disease. Furthermore, impaired FDM seems to be readily reversible by the treatment of risk factors such as high cholesterol and cigarette smoking $[9,10]$. There have been no intervention studies based on impaired FDM, and it is still an open question whether endothelial dysfunction is an independent risk factor or whether it just reflects the presence of increased risk, readily measured by other methods. Obviously, impaired FDM has no place in clinical decision making at the present time.

What about IMT, then? As shown by Srámek et al. [1] and other investigators, the methodology is noninvasive, simple, highly reproducible and correlated with CAD. Large-scale prospective studies are needed to assess the place of ITM in risk stratification. Is there a clinical application? It is highly tempting to answer this question in the affirmative but, regrettably, the answer is still no. While treatment may reduce IMT, the proof that reducing IMT results in reduced CAD burden is still lacking. What we need are randomized controlled trials of interventions for increased ITM, controlling for the classical coronary risk factors and showing not only reduction in artery wall dimensions but also in the occurrence of clinical endpoints. Such studies would need to be large, and would consequently be expensive and time-consuming. Unfortunately, there is no easy way out.

\section{References}

1 Srámek A, Reiber JHC, Rosendaal FR: Intimamedia thickness measurements in the carotid and femoral artery as an indicator of symptomatic coronary atherosclerosis. Heart Drug 2001; 1:249-254.

2 Wilson PWF, D'Agostino RB, Levy D, Belanger AM, Silbershatz H, Kannel WB: Prediction of coronary heart disease using risk factor categories. Circulation 1998;97:1506-1511.

3 Pedersen TR, Wilhelmsen L, Faergeman O, Strandberg TE, Thorgeirsson G, Troedsson L, Kristianson J, Berg K, Cook TJ, Haghfelt T, Kjekshus J, Miettinen T, Olsson AG, Pyorala $\mathrm{K}$, Wedel H: Follow-up study of patients randomized in The Scandinavian Simvastatin Survival Study (4S) of cholesterol lowering. Am J Cardiol 2000;86:257-262.
4 Hansson L, Lindholm LH, Ekblom T, Dahlof B, Lanke J, Schersten B, Wester PO, Hedner T, de Faire U: Randomised trial of old and new antihypertensive drugs in elderly patients: Cardiovascular mortality and morbidity in the Swedish Trial in Old Patients with Hypertension-2 study. Lancet 1999;354:1751-1756.

5 Rumberger JA, Sheedy PF, Breen JF, Schwartz RS: Electron beam computed tomographic calcium score cutpoints and severity of associated angiographic lumen stenosis. J Am Coll Cardiol 1997;29:1542-1548.

6 Keelan PC, Bielak LF, Ashai K, Jamjoum LS, Denktas AE, Rumberger JA, Sheedy PF II, Peyser PA, Schwartz RS: Long-term prognostic value of coronary calcification detected by electron-beam computed tomography in patients undergoing coronary angiography. Circulation 2001;104:412-417.

7 Grundy SM: Coronary calcium as a risk factor: Role in global risk assessment (editorial comment). J Am Coll Cardiol 2001;37:1512-1515.
8 Celermajer DS, Sorensen KE, Bull C, Robinson J, Deanfield JE: Endothelium-dependent dilatation in the systemic arteries of asymptomatic subjects relates to coronary risk factors and their interaction. J Am Coll Cardiol 1994;24: 1468-1474.

9 Dupuis J, Tardif JC, Cernacek P, Theroux P. Cholesterol reduction rapidly improves endothelial function in acute coronary syndromes. The RECIFE (reduction of cholesterol in ischemia and function of the endothelium) trial. Circulation 1999;99:3227-3233.

10 Lekakis J, Papamichael C, Vemmos C, Stamatelopoulos K, Voutsas A, Stamatelopoulos S: Effects of acute cigarette smoking on endothelium-dependent arterial dilatation in normal subjects. Am J Cardiol 1998;81:1225-1228. 